\title{
Ultrafine-Grained Plates of Al-Mg-Si Alloy Obtained by Incremental Equal Channel Angular Pressing: Microstructure and Mechanical Properties
}

\author{
MARTA LIPINSKA, WITOLD CHROMINSKI, LECH OLEJNIK, JACEK GOLINSKI, \\ ANDRZEJ ROSOCHOWSKI, and MALGORZATA LEWANDOWSKA
}

\begin{abstract}
In this study, an $\mathrm{Al}-\mathrm{Mg}-\mathrm{Si}$ alloy was processed using via incremental equal channel angular pressing (I-ECAP) in order to obtain homogenous, ultrafine-grained plates with low anisotropy of the mechanical properties. This was the first attempt to process an Al-Mg-Si alloy using this technique. Samples in the form of $3 \mathrm{~mm}$-thick square plates were subjected to I-ECAP with the $90 \mathrm{deg}$ rotation around the axis normal to the surface of the plate between passes. Samples were investigated first in their initial state, then after a single pass of I-ECAP, and finally after four such passes. Analyses of the microstructure and mechanical properties demonstrated that the I-ECAP method can be successfully applied in Al-Mg-Si alloys. The average grain size decreased from 15 to $19 \mu \mathrm{m}$ in the initial state to below $1 \mu \mathrm{m}$ after four I-ECAP passes. The fraction of high-angle grain boundaries in the sample subjected to four I-ECAP passes lay within 53 to 57 pct depending on the examined plane. The mechanism of grain refinement in $\mathrm{Al}-\mathrm{Mg}-\mathrm{Si}$ alloy was found to be distinctly different from that in pure aluminum with the grain rotation being more prominent than the grain subdivision, which was attributed to lower stacking fault energy and the reduced mobility of dislocations in the alloy. The ultimate tensile strength increased more than twice, whereas the yield strength was more than threefold. Additionally, the plates processed by I-ECAP exhibited low anisotropy of mechanical properties (in plane and across the thickness) in comparison to other SPD processing methods, which makes them attractive for further processing and applications.
\end{abstract}

DOI: $10.1007 / \mathrm{s} 11661-017-4258-8$

(C) The Author(s) 2017. This article is an open access publication

\section{INTRODUCTION}

THE increasing interest in the materials with the ultrafine-grained (UFG) structure is stimulated by their enhanced mechanical strength. This phenomenon is caused by the elevated amount of grain boundaries acting as obstacles for moving dislocations. ${ }^{[1]}$ In case of metallic materials, they are frequently produced by employing severe plastic deformation (SPD) processes, which induces grain refinement. ${ }^{[2,3]}$

MARTA LIPINSKA, WITOLD CHROMINSKI, and MALGORZATA LEWANDOWSKA are with the Faculty of Materials Science and Engineering, Warsaw University of Technology, Woloska 141, 02-507 Warsaw, Poland. Contact e-mail: marta.lipinska@inmat.pw.edu.pl LECH OLEJNIK and JACEK GOLINSKI are with the Institute of Manufacturing Processes, Warsaw University of Technology, Narbutta 85, 02-524 Warsaw, Poland. ANDRZEJ ROSOCHOWSKI is with the Design, Manufacture and Engineering Management, University of Strathclyde, 75 Montrose Street, Glasgow G1 1XJ, UK.

Manuscript submitted December 26, 2016.

Article published online July 31, 2017
One of the most popular SPD methods is the equal channel angular pressing (ECAP), for the overview see. ${ }^{[3]}$ Although this method is well described and proven to be efficient for grain refinement of many metallic materials, including pure aluminum ${ }^{[4,5]}$ and its alloys, ${ }^{[6-8]}$ it features some deficiencies and is a subject of various modifications, such as rotary die, ${ }^{[9]}$ additional back pressure, ${ }^{[10]}$ or matrix with parallel channels. ${ }^{[1]}$ The major deficiency includes low productivity of batch process. In this context, a number of attempts have been made to develop a continuous process, the so-called Conform ECAP. ${ }^{[12]}$ In addition, in its traditional version, ECAP can efficiently deform billets in the form of bars or rods. However, for many industrial applications, e.g., deep drawing or superplastic forming, a thin and flat semi-product is required. Therefore, there is a need to develop an efficient process to produce UFG plates. It should be noted here that UFG materials have a potential to exhibit the so-called fast superplasticity, i.e., ability to superplastic deformation at high strain rates and strain rate sensitivities close to $0.5 .^{[13]}$ This was already proven for a number of ECAP processed alloys. $^{[14-16]}$ 
Plates with ultrafine-grained structure can be produced using accumulative roll bonding method (ARB) ${ }^{[17]}$ It has been proven that ARB is an effective method of grain refinement in aluminum and its alloys. ${ }^{[18,19]}$ Nevertheless, the limitations of this method, such as cracks appearing at higher cycles ${ }^{[20]}$ or anisotropy of mechanical properties, create a need for the development of other methods. UFG thick plates can be obtained using conventional ECAP; ${ }^{[21]}$ however, for thin products, modifications of this process are required, e.g., equal channel angular sheet extrusion. ${ }^{[22,23]}$ Another option, which has been recently introduced, is Incremental ECAP (I-ECAP). ${ }^{[24]}$ The main idea of this method is to apply a plastic strain in a series of small deformation increments, which are based on a simple shear (in terms of deformation, the process is thus equivalent to conventional ECAP). The separation of feeding and deformation steps reduces the friction during feeding, which enables the processing of very long or even continuous billets. Similar to the conventional ECAP, this incremental method has the ability to apply different routes. For flat billets, the route B cannot be applied; however, for square plates, it is possible to employ a deformation route based on a rotation around the axis normal to the plate (the $Z$ axis). In this case, there is a possibility to change the deformation direction, which was proven for pure aluminum to enhance the process of grain refinement and the formation of high-angle grain boundaries (HAGBs - defined as grain boundaries with misorientation angle higher than $15 \mathrm{deg}) .^{[25,26]}$ The uniform microstructure obtained in I-ECAP process offers the possibility to produce plates with isotropic mechanical properties. Although there is a vast number of papers devoted to conventional ECAP, I-ECAP is rather a new option for producing UFG materials and requires further investigation. The present work is the first attempt to produce the UFG plates made of a commercially available Al-Mg-Si alloy (AA6060) using the I-ECAP method.

There are plenty of studies about SPD processing of Al-Mg-Si alloys, such as ECAP ${ }^{[27-29]}$ or high pressure torsion (HPT). ${ }^{[30-32]}$ However, the main emphasis is placed on the combination of grain boundaries strengthening with an age hardening ${ }^{[27,33]}$ or optimizing mechanical and electrical properties by applying aging process. ${ }^{[32,34]}$ It was shown, that applying these two strengthening mechanisms can enhance both mechanical strength and electrical conductivity. Since most of the literature data concerning Al-Mg-Si alloys are focused on the precipitation behavior in ultrafine-grained structure, there is a lack of works devoted solely to the evolution of grain structure. The present study fills this gap since it is concentrated on the changes in grains shape and size and the evolution of grain boundaries misorientations. Also, a goal of this work is to compare the process of grain refinement in pure aluminum and Al-Mg-Si alloy, as they differ in stacking fault energy. ${ }^{[35]}$ Furthermore, the mechanical properties of the I-ECAP processed alloy were determined with a special emphasis on its homogeneity, which allows to estimate the anisotropy of mechanical properties. Together with the microstructure characterization, this paper gives a complex study of a potential of incremental ECAP method as a method to obtain UFG structure not only in pure aluminum, but also in $\mathrm{Al}-\mathrm{Mg}-\mathrm{Si}$ alloy in plate-shaped samples.

\section{MATERIAL AND METHODS}

The examined material was an AA6060 with a chemical composition presented in Table I. Samples in the form of rolled sheets were homogenized at $723 \mathrm{~K}$ $\left(450{ }^{\circ} \mathrm{C}\right.$ ) for 2 hours and then furnace cooled. Subsequently, the plates were subjected to up to four passes of I-ECAP with the channel angle of $90 \mathrm{deg}$ at room temperature. The dimensions of the samples were $3 \times 62 \times 62 \mathrm{~mm}$. Figure 1 shows the tool configuration used for the I-ECAP processing of such square plate. The input of the angular channel is formed by halves 1 and 2 of the split die, whereas the perpendicular outlet channel is partly placed in the upper part of half 1 of this die. One wall of the outlet is cyclically closed and opened by the reciprocating punch 3 . The punch shears the material fed stepwise by pusher 4 and directs it into the perpendicular output channel. Hence, the inner radius of the angular channel is defined by the dimension of the edge at the corner in half 1 of the split die. The outer radius results from the applied movement of punch 3 . Having left the I-ECAP machinery, Plate 5 features shape details, which are typical for the ones obtained via the conventional ECAP. These features are the rounded front edge and the rear edge shaped by the forming tools - the latter is shown on a larger scale in Figure 1.

The working area shown in Figure 1 is characterized by the right-handed system of the xyz axes, which is associated with planes characteristic of the ECAP processed parts. Namely, $\mathrm{X}$ - the cross section (rear face), $Y$ - the longitudinal section (side face), and $\mathrm{Z}$ - the plane of the plate (top face). According to the xyz coordinate system, the square plates were rotated in the same direction through $90 \mathrm{deg}$ around the $Z$ axis between each pass. This pressing route resulted in the changing position of the shearing plane, which is schematically shown in Figure 2.

The microstructure investigation was conducted for samples in the initial state, then after one and four passes of I-ECAP, which equals the equivalent strain of $0,1.15$, and 4.6, respectively. To this end, electron backscatter diffraction (EBSD) using an analytical scanning electron microscope Hitachi SU-70 with the accelerating voltage of $20 \mathrm{kV}$ was used. For detailed microstructure investigations, Transmission Electron Microscope (TEM) JEOL JEM 1200 with the accelerating voltage of $120 \mathrm{kV}$ was used. Thin foils for both techniques were prepared using a wire saw, then ground down to $150 \mu \mathrm{m}$, and electro-polished using Struers Tenupol-5 system operating at a voltage of $35 \mathrm{~V}$ at a temperature of $278 \mathrm{~K}\left(5^{\circ} \mathrm{C}\right)$. The solution containing ethanol, perchloric acid, butyl glycol, and distilled water was used. For EBSD, disks were additionally ion polished. The scans were performed with a $500 \mathrm{~nm}$ step for the material in the initial condition, and $80 \mathrm{~nm}-$ for 
Table I. The Chemical Composition of AA6060

\begin{tabular}{lcccccccccccc}
\hline Element & $\mathrm{Fe}$ & $\mathrm{Si}$ & $\mathrm{Cu}$ & $\mathrm{Zn}$ & $\mathrm{Ti}$ & $\mathrm{Mn}$ & $\mathrm{Mg}$ & $\mathrm{Ni}$ & $\mathrm{Cr}$ & $\mathrm{Pb}$ & $\mathrm{Al}$ \\
\hline Content (wt pct) & 0.19 & 0.43 & 0.006 & 0.009 & 0.005 & 0.004 & 0.57 & 0.004 & 0.008 & 0.002 & balance \\
\hline
\end{tabular}

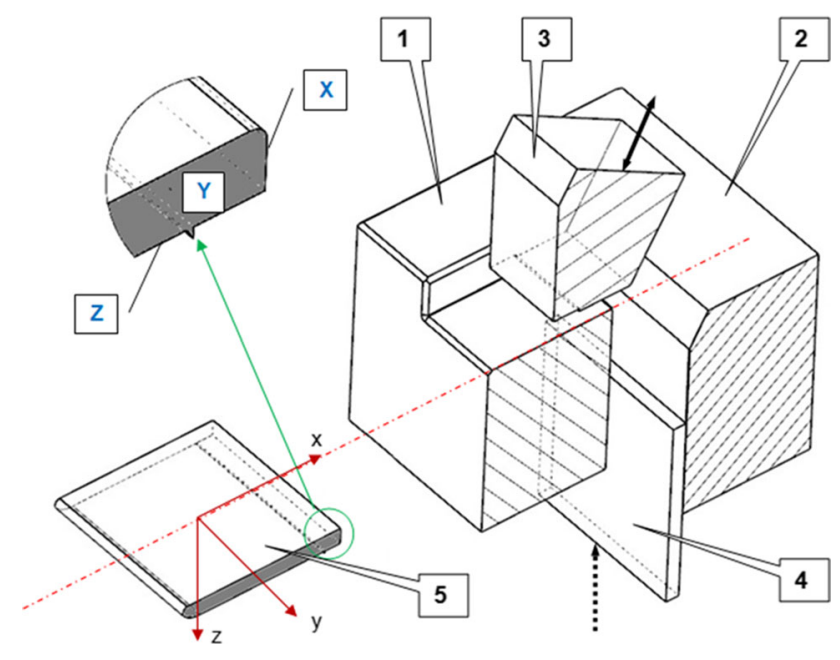

Fig. 1-The configuration of I-ECAP tools for processing square plates: 1 fitted die, 2 clamping die, 3 punch, 4 pusher, 5 pressed plate (tools 1 and 3 shown in an axial longitudinal cross section).

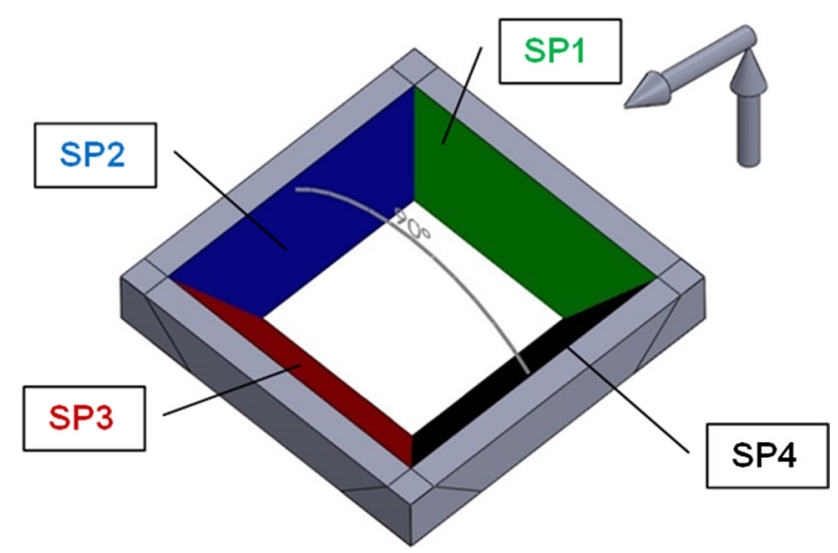

Fig. 2-Positions of shearing planes (SP) in a square plate during four consecutive passes through I-ECAP tools.

samples after SPD. The scanned area in all cases contained about 160,000 points.

From EBSD measurements, the quantitative microstructural parameters were determined. Since the SPD processed materials contain relatively large fraction of Low-Angle Grain Boundaries (LAGBs defined as grain boundaries with misorientation angle ranging from 2 to $14 \mathrm{deg}$ ), two parameters were used to quantify the grain size. In the first approach, both LAGBs and HAGBs were taken into consideration. The resulting parameter called the equivalent grain diameter, $d$, was defined as the diameter of a circle whose area is equal to that of the investigated grain. The grain size was also determined taking into account only HAGBs. In this approach, the parameter was denoted as $d_{\text {HAGBs }}$. From these measurements, the mean value, coefficient of variation $C V$ (a ratio of standard deviation to the mean value $d)$, and the grain elongation factor $\alpha\left(d_{\max } / d\right)$ were determined.

In order to characterize the mechanical properties, tensile tests and microhardness measurements were carried out. In the case of the tensile test, flat mini samples were used, as described in Reference 36. The tensile samples were cut from two directions - transverse and longitudinal to the direction of the last pass. Digital image correlation (DIC) was used for accurate strain determination. Microhardness measurements were carried out linearly from the top to the bottom surface in the $\mathrm{Y}$ plane of samples under a load of $200 \mathrm{~g}$ for 15 seconds. Each surface before the experiment was grinded and polished to obtain a smooth surface. For each sample, measurements were taken every $0.3 \mathrm{~mm}$, which gives 8 points per sample.

\section{RESULTS}

\section{A. Microstructure}

The representative EBSD orientation maps for the initial sample are shown in Figure 3. HAGBs are highlighted in black while less distinct, gray boundaries are LAGBs. The initial sample possesses coarse grains, which are close to equiaxial, especially when observed on the $\mathrm{X}$ and $\mathrm{Y}$ planes, as quantified by the elongation factor $\alpha$ presented in Table II. The average grain size measured using both $d$ and $d_{\text {HAGBs }}$ is in the range of 15 to $19 \mu \mathrm{m}$ and depends on the observation plane (is the highest for the $\mathrm{Z}$ plane). It is also higher by approximately $2 \mu \mathrm{m}$ for $d_{\text {HAGBs }}$ when compared to $d$, since even in coarse-grained materials there are some LAGBs. The coefficient of variation equals 0.7 to 0.8 , which indicates rather high grain size diversity. The fraction of HAGBs (Table III) is relatively high, typical for coarse-grained structures and varies between 85 and 92 pct, depending on the observation plane.

Figure 4 illustrates the representative orientation maps of the $\mathrm{X}, \mathrm{Y}$, and $\mathrm{Z}$ planes for samples after one and four I-ECAP passes. The strain imposed during the first pass induced microstructural changes typical for plastic deformation. In the X plane, one can distinguish coarse grains with the LAGB structure in their interiors. The structure in the $\mathrm{Y}$ plane is characteristic for materials processed by ECAP. Grains are elongated and inclined with respect to the shear direction. The fraction of HAGBs is lower than 30 pct for all the planes. It should be noted that the strain imposed in the first pass was high enough to induce grain refinement. In each section, one can see some grains, which exhibit a 

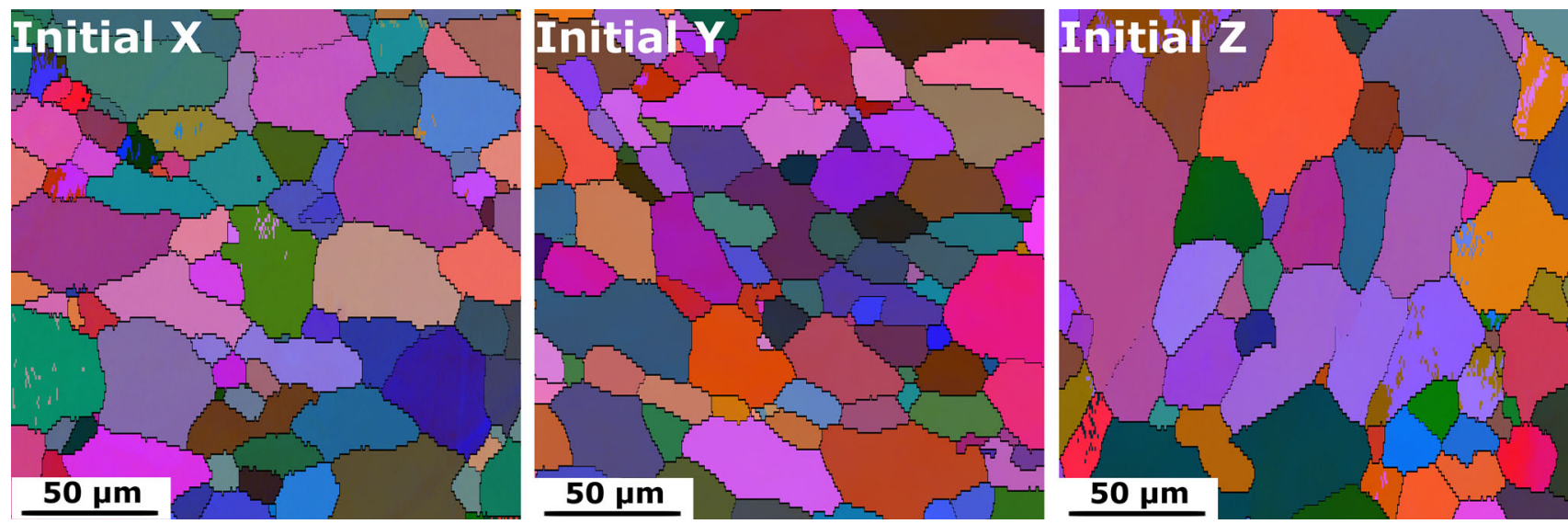

Fig. 3-EBSD orientation maps of the initial material, planes $\mathrm{X}, \mathrm{Y}$, and $\mathrm{Z}$.

Table II. Quantitative Parameters Describing the Microstructure: $d$-Average Grain Diameter, $C V$-Coefficient of Variation, $\alpha$-Grain Elongation Factor-All Measured for LABGs and HAGBs, $d_{\text {HAGBs }}$-Average Grain Diameter Only for HAGBs

\begin{tabular}{lccccccccc}
\hline Parameter & Initial X & Initial Y & Initial Z & $1 \mathrm{X}$ & $1 \mathrm{Y}$ & $1 \mathrm{Z}$ & $4 \mathrm{X}$ & $4 \mathrm{Y}$ & $4 \mathrm{Z}$ \\
\hline$d(\mu \mathrm{m})$ & 15.62 & 15.47 & 18.80 & 1.28 & 1.33 & 1.42 & 0.89 & 0.90 & 0.92 \\
$d_{\text {HAGBs }}(\mu \mathrm{m})$ & 17.60 & 16.93 & 20.21 & 2.74 & 3.43 & 3.62 & 1.16 & 1.14 & 1.17 \\
$\mathrm{CV}$ & 0.78 & 0.69 & 0.77 & 1.64 & 1.57 & 1.37 & 0.71 & 0.72 & 0.70 \\
$\alpha$ & 1.48 & 1.51 & 1.60 & 1.59 & 1.64 & 1.68 & 1.43 & 1.48 & 1.47 \\
\hline
\end{tabular}

Table III. The Fraction of HAGB (Pct) on Each Plane for the Initial and Deformed Al-Mg-Si Alloy

\begin{tabular}{lccccccccc}
\hline & Initial X & Initial Y & Initial Z & $1 \mathrm{X}$ & $1 \mathrm{Y}$ & $1 \mathrm{Z}$ & $4 \mathrm{X}$ & $4 \mathrm{Y}$ & $4 \mathrm{Z}$ \\
\hline HAGBs (pct) & 85.2 & 92.3 & 87.4 & 27.7 & 27.4 & 24.3 & 57.4 & 54.6 & 53.2 \\
\hline
\end{tabular}

size close to $1 \mu \mathrm{m}$. However, the volume fraction of such grains does not exceed a few percent.

After one I-ECAP pass, the average grain size $d$ decreased significantly from 15 to $19 \mu \mathrm{m}$ in the initial condition to about 1.3 to $1.4 \mu \mathrm{m}$ while $d_{\mathrm{HAGBs}}$ was reduced from 17 to $20 \mu \mathrm{m}$ to about 3 microns. Such a large difference in these two parameters describing the grain size can be attributed to a high fraction of LAGBs, which constitutes more than 70 pct of all grain boundaries. The grain size diversity is very high, as described by the high values of $\mathrm{CV}$, amounting to 1.37 to 1.64 . The elongation factor reveals the highest value for the $\mathrm{X}$ plane, whereas the lowest was for the $\mathrm{Z}$ plane, comparable for the material in the initial state.

Processing up to four I-ECAP passes caused further refinement of the grains, as quantified by parameters presented in Table II for all planes. The grain structure became more equiaxial and comparable for different planes. The average grain size decreased below $1 \mu \mathrm{m}$ when quantified by $d$ and to $1.1 \mu \mathrm{m}$ for $d_{\text {HAGBs. }}$. In addition, the diversity of grain size is reduced, as quantified by the $\mathrm{CV}$ factor, which became comparable or even lower than for the initial sample, depending on examined plane. Nevertheless, there is a fraction that contains some grains that were significantly elongated but of a smaller size in comparison with the previous state. The elongation factor is lower than in the initial state and equals 1.43 to 1.48 . The fraction of HAGBs increased to about 53 to $57 \mathrm{pct}$ because of grain fragmentation.

Distributions of misorientation angles are illustrated in Figure 5, for each plane separately. In each diagram, all three states are shown. The initial sample, marked in black, exhibits the distribution of misorientation angles close to the Mackenzie plot, ${ }^{[37]}$ typical for random orientation distribution. As a result, a very high fraction of HAGBs is present in this sample (see Table III). After one pass (gray bars), most of grain boundaries are of a low-angle type while after four passes the majority of grain boundaries feature a misorientation angle higher than 15 deg but still there is a significant fraction of LAGBs. The highest peak in the histogram is observed for the boundaries with the misorientation angles of 6-10 deg, which means a shift towards higher misorientation angles in comparison to sample after one I-ECAP pass.

Discrete $\{111\}$ pole figures from the $\mathrm{Y}$ planes of investigated samples are gathered in Figure 6. They show a microtexture of the regions previously depicted in orientation maps. In the initial state, random texture can be concluded based on the image shown in Figure 6(a). After the first I-ECAP pass two components related with a simple shear deformation can be noticed. They are the A fiber- $\{111\}\langle\mathrm{uvw}\rangle$ and a 

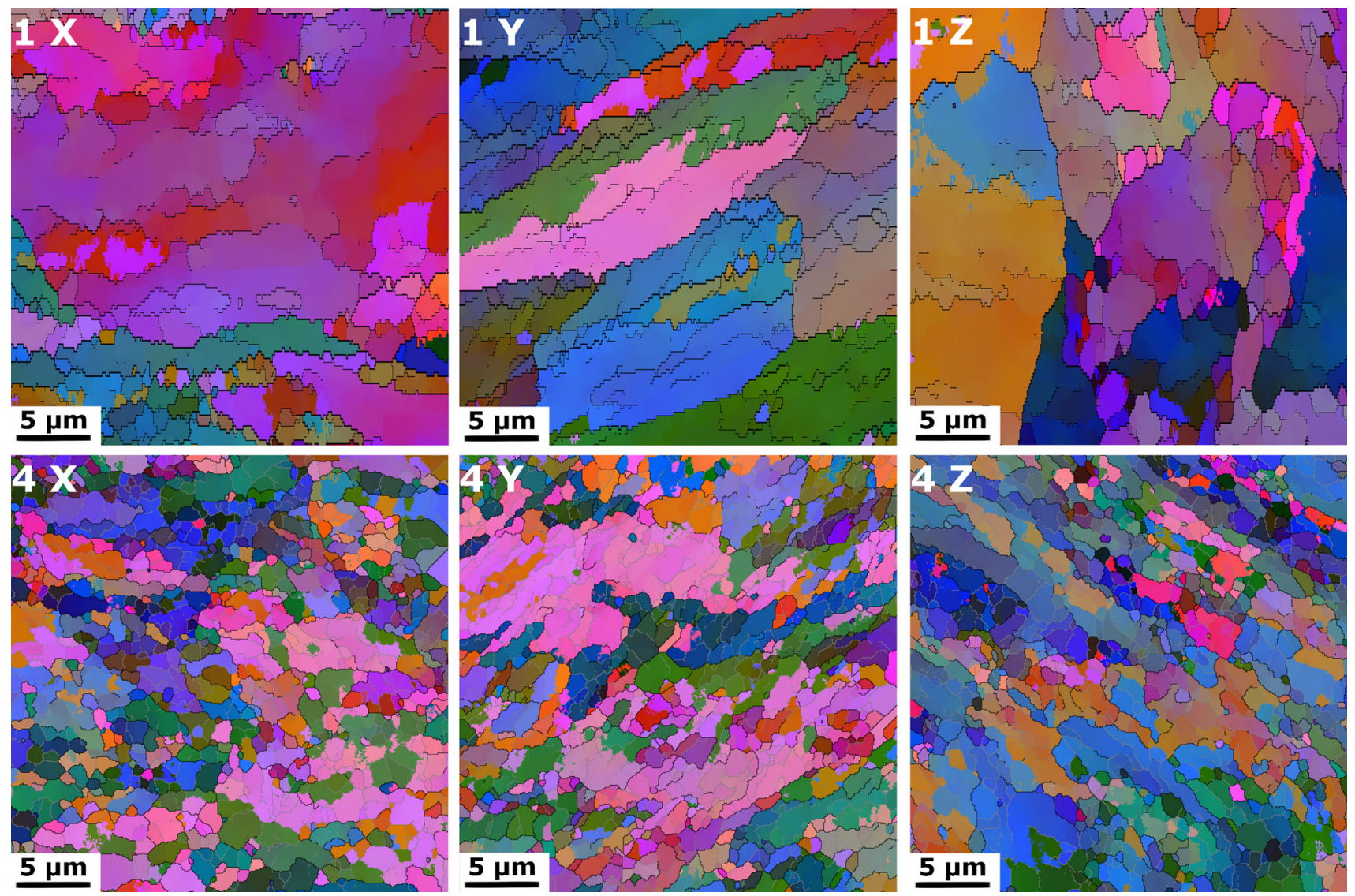

Fig. 4-EBSD orientation maps of the material after one and four I-ECAP passes with the designation in left top corner.

combination of $\mathrm{A}$ and $\mathrm{B}$ fibers, denoted as $\mathrm{A} /$ B- $\{111\}\langle 110\rangle$ following notation proposed in Reference 38. The other components are rather faint when compared to these two. Such a result, i.e., the presence of components related with simple shear is frequently observed in samples subjected to one ECAP pass of $\mathrm{Al}^{[5,38]}$ or other fec metals. ${ }^{[39]}$ After the fourth pass, texture randomizes, however, two components related with a simple shear can be spotted-A/B and $\mathrm{C}-\{100\}\langle 110\rangle$. Other orientations can be interpreted as random and are the result of sample rotation in subsequent passes, which impose different shearing planes. Despite the fact that the 'global texture' has not been investigated in this study, it can be stated that AA6060 subjected to I-ECAP follows the tendencies frequently reported in the literature. The texture measured in the entire volume of the billet randomizes but locally components typical for simple shear can be identified. ${ }^{[38,40-43]}$

\section{B. Mechanical Properties}

The representative tensile stress-strain curves (engineering notation) are presented in Figure 7 . The average values of ultimate tensile strength (UTS), yield strength (YS), elongation to break (A), and uniform elongation $\left(\mathrm{A}_{\mathrm{U}}\right)$ are summarized in Table IV. The properties were measured in longitudinal (LD $=x$ axis as in Figure 1) and transverse $(\mathrm{TD}=y$ axis as in Figure 1) directions.
The initial sample exhibits the highest elongation to break and uniform elongation and the lowest values of UTS and YS. I-ECAP results in a significant improvement of mechanical strength, i.e., YS increased by 260 pct while UTS - by 140 pct. This improvement was achieved at the expense of ductility, which decreased from 30 pct to about 8 pct. However, elongation did not decrease with increased deformation. Moreover, one can even find that elongation is higher for the sample subjected to four passes than for the one subjected only to the first pass. It should also be noted that there is only a slight difference between measured values in longitudinal and transverse directions for samples subjected to four passes. UTS and YS are slightly higher in the transverse direction in all cases.

Such changes in mechanical properties are typical for SPD processed materials, as proved in numerous papers before, for AA $7050^{[8]}$ or AA1050. ${ }^{[44]}$ In addition, rapid necking is observed for samples with the UFG structure, which is typical for materials after the SPD processing, and has been achieved for pure aluminum. ${ }^{[21,45]}$ The flow stress quickly achieves the maximum value and then decreases gradually. It indicates that necking occurs early and further deformation is accompanied by a deepening neck. Therefore, the elongation to break is much reduced in comparison to the coarse-grained material and does not exceed 10 pct.

The results of microhardness measurements are presented in Figure 8 as a function of distance from the top 

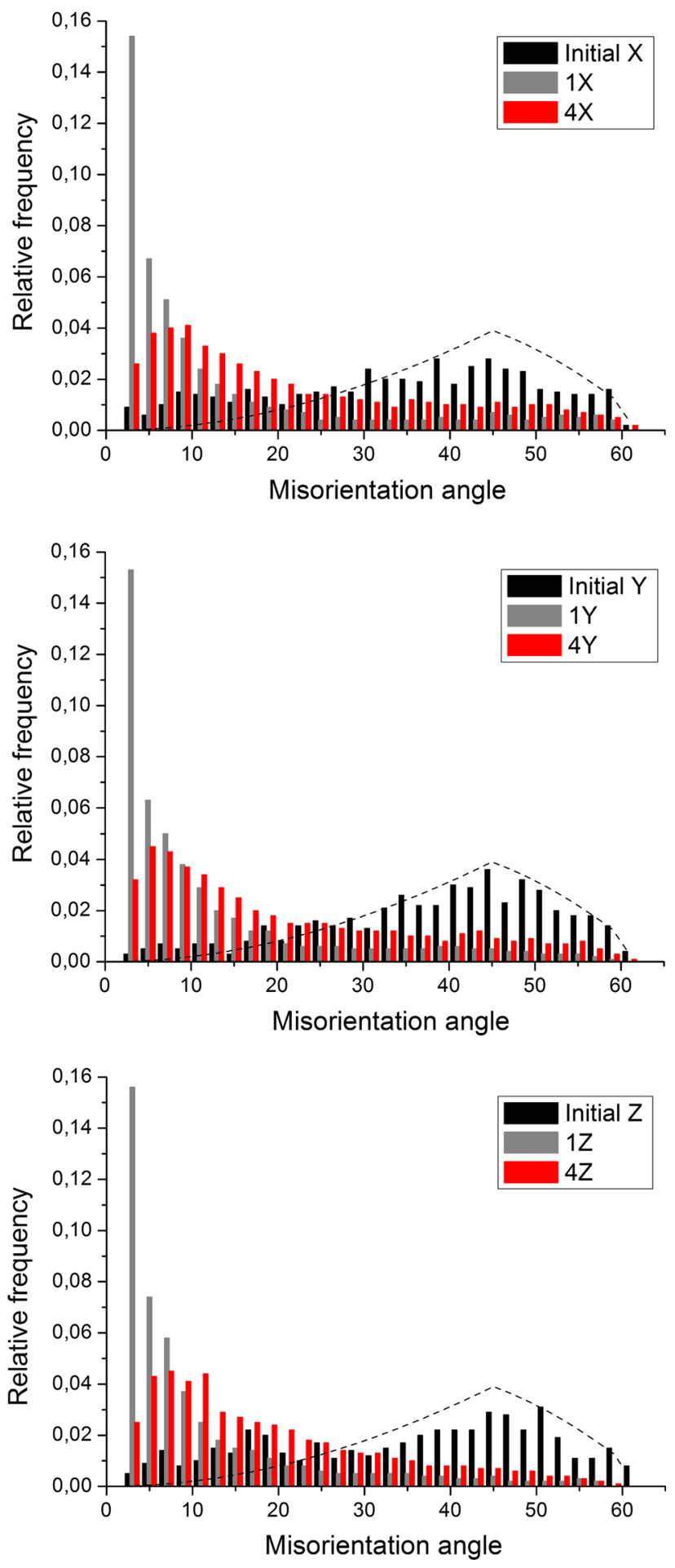

Fig. 5-Misorientation angle distributions for initial and deformed samples divided into planes.

surface, which has contact with the punch during deformation (see Figure 1). The measurements were taken on the Y plane. As it can be seen, the microhardness increases with subsequent passes. In the case of the initial sample, the value of microhardness is homogenous throughout the sample thickness. The average value is $43 \mathrm{Hv} 0.2$ and the coefficient of variation equals
2.1 pct. After I-ECAP, the microhardness values increase to 61 and $73 \mathrm{Hv} 0.2$ for the samples subjected to one and four passes, respectively. In these samples, there are distinct differences between top and bottom surfaces. The top surface, which has contact with the punch, reveals higher values of microhardness than the bottom one. The character of the line is similar for both samples after I-ECAP. For the sample subjected to the first pass, this difference equals $3.5 \mathrm{Hv0.2}$. For the sample, which underwent four passes this difference equals 4.3 Hv0.2. Nevertheless, the coefficient of variation is bigger for less deformed material-3.5 to 2.7 pct for the material subjected to four passes.

\section{DISCUSSION}

\section{A. Grain Refinement Mechanism}

For grain refinement, it is required that new HAGBs are created. During SPD, high-angle grain boundaries may form via the extension of pre-existing boundaries in proportion to the $\operatorname{strain}^{[46]}$ or by means of grain subdivision. ${ }^{[47]}$ These processes take place simultaneously. The main factor that influences the advancement in the structure refinement and HAGB formation is the imposed strain, which was described in detail in Reference 48.

In the initial sample (a rolled sheet with subsequent annealing), the microstructure consists of HAGBs in the amount of about 90 pct. The average grain size equals 15 to $19 \mu \mathrm{m}$. The grains are close to equiaxial for all planes. After the first pass of I-ECAP with the imposed strain of 1.15 , primary cell blocks bands with varied misorientations can be found. Such a microstructure is typical for initial ECAP stage. Some of the boundaries have already achieved misorientation higher than $15 \mathrm{deg}$ and become new HAGBs. Nevertheless, the majority of the boundaries is still of the low-angle type as shown in Figure 5. As a complement to the EBSD analysis, the representative TEM microstructures after the first pass of I-ECAP are presented in Figure 9 for each plane separately. The X plane is characterized by coarse grains surrounded with HAGBs and dislocation substructures in their interiors. The beginning of grain refinement process is clearly observed. The microstructures seen in planes X and Y (Figures 9(a) and (b)) are similar. However, the distinct difference is the inclination of the grains due to differences in shearing patterns in ECAP. ${ }^{[49]}$ As noticed from texture measurements some components related to simple shear can be noticed on the Y plane, thus elongated grains can be interpreted as a result of shearing force operation (Figure 6(b)). After a single pass, on the $\mathrm{Y}$ plane the slip traces appear at $45 \mathrm{deg}$ relatively to the deformation direction-direction of shearing force. In the case of the $\mathrm{Z}$ plane (Figure 9(c)), the grain refinement seems to be the least distinct. Nevertheless, grains reveal a more equiaxial shape but are of a bigger size. It should also be noted that free dislocations (neither involved in dislocation cells nor in dislocation boundaries) can be seen in grain and subgrain interiors. 


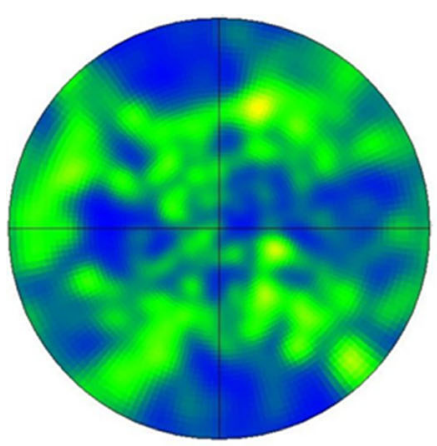

(a)

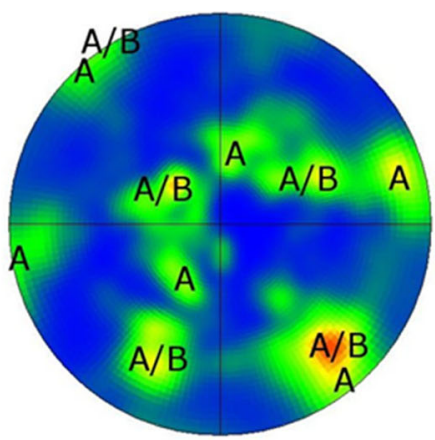

(b)

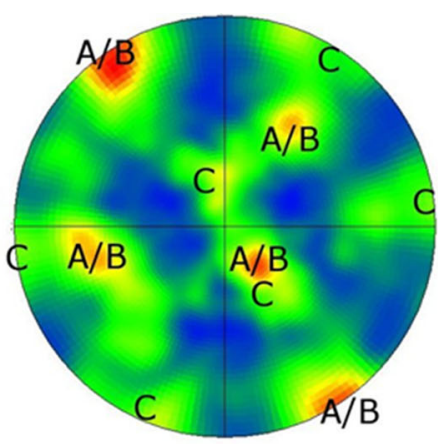

(c)

Fig. $6-\{111\}$ pole figures from Y plane of $(a)$ initial sample, after $(b)$ one and $(c)$ four passes of I-ECAP.

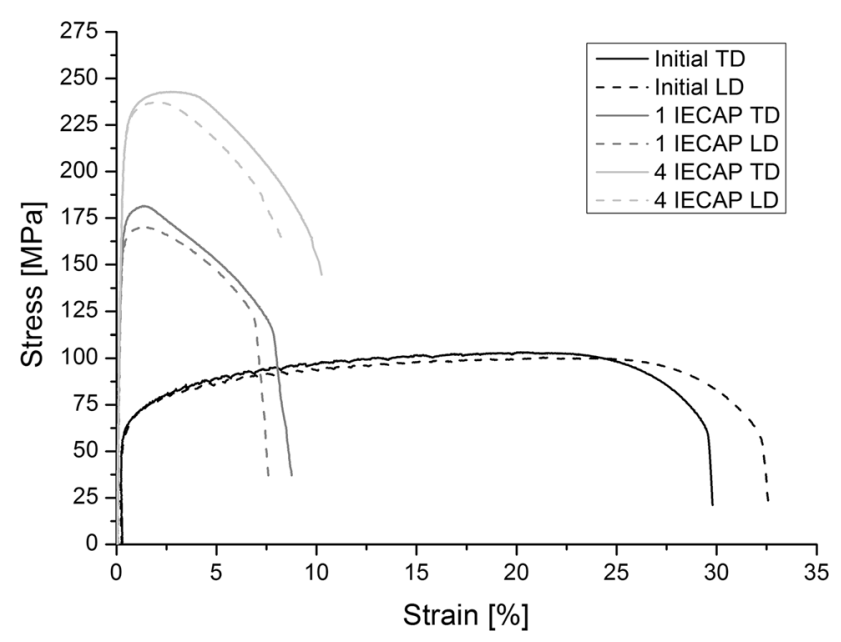

Fig. 7-Representative engineering stress-strain curves of TD - transverse direction and LD - longitudinal direction for each state.

Table IV. Values of Ultimate Tensile Strength (UTS), Yield Strength (YS), Elongation to Break (A), and Uniform Elongation $\left(\mathbf{A}_{\mathbf{U}}\right)$

\begin{tabular}{lccrr}
\hline Sample & $\begin{array}{c}\mathrm{UTS} \\
(\mathrm{MPa})\end{array}$ & $\begin{array}{c}\mathrm{YS} \\
(\mathrm{MPa})\end{array}$ & $\begin{array}{c}\mathrm{A}_{\mathrm{U}} \\
(\mathrm{Pct})\end{array}$ & $\begin{array}{c}\mathrm{A} \\
(\mathrm{Pct})\end{array}$ \\
\hline Initial transverse & 103 & 62 & 20.4 & 30.4 \\
Initial longitudinal & 99 & 61 & 19.9 & 30.3 \\
1 I-ECAP Transverse & 182 & 170 & 1.3 & 8.2 \\
1 I-ECAP Longitudinal & 172 & 163 & 1.4 & 7.7 \\
4 I-ECAP Transverse & 242 & 221 & 2.7 & 9.1 \\
4 I-ECAP Longitudinal & 236 & 217 & 2.2 & 7.6 \\
\hline
\end{tabular}

Figure 10 shows representative microstructures observed in TEM on the $\mathrm{X}, \mathrm{Y}$, and $\mathrm{Z}$ planes after four passes of I-ECAP. The main difference in comparison to the microstructure after one pass is the apparent grain refinement. Most of the grains are elongated, especially in the $\mathrm{X}$ and $\mathrm{Y}$ planes. Once again, the elongation of grains observed in the $\mathrm{Y}$ plane can be related to simple shear deformation, as the long direction is in accordance to the direction of shearing force. Inside the grains, one can see free dislocations and dislocation substructures.

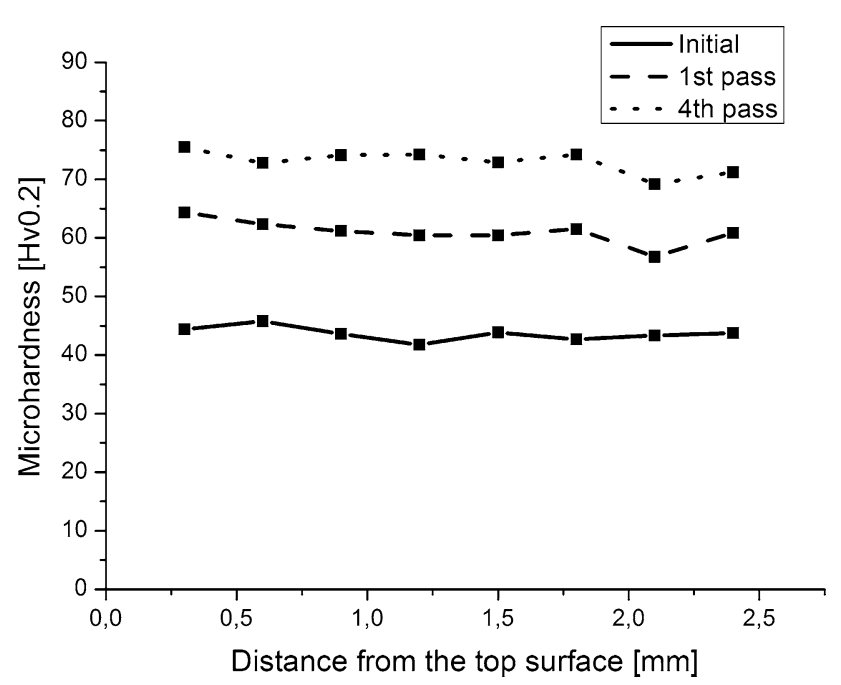

Fig. 8-The microhardness in a function of distance from the top surface of the sample (punch).

After one pass of I-ECAP, the process of grain refinement is at its initial stage. After four passes, the structure is definitely more developed in terms of grain refinement. It was proved by the quantification of microstructure (Table II) and misorientation angle distribution (Figure 5). The $\mathrm{Z}$ plane is characterized by a more equiaxial microstructure, but is less refined and not fully defined. Many boundaries are still of a low misorientation angle. Further deformation could cause further progression in the grain refinement process.

In comparison to the commercially pure aluminum, the grain refinement in the 6060 aluminum alloy occurs differently. The main difference between pure aluminum and the Al-Mg-Si alloy in terms of the plastic deformation mechanism is dislocation mobility, which directly influences deformation structures. It was shown for $\mathrm{Ni}$ alloys deformed by rolling that the stacking fault energy has a crucial impact on the post-deformation structure. ${ }^{[50]}$ A pure metal features more mobile dislocations, which can easily change slip planes during deformation. Thus, such material does not store free dislocations between dislocation boundaries. When the stacking fault energy was lowered by adding alloying elements, the mobility of dislocations was reduced and they could not 

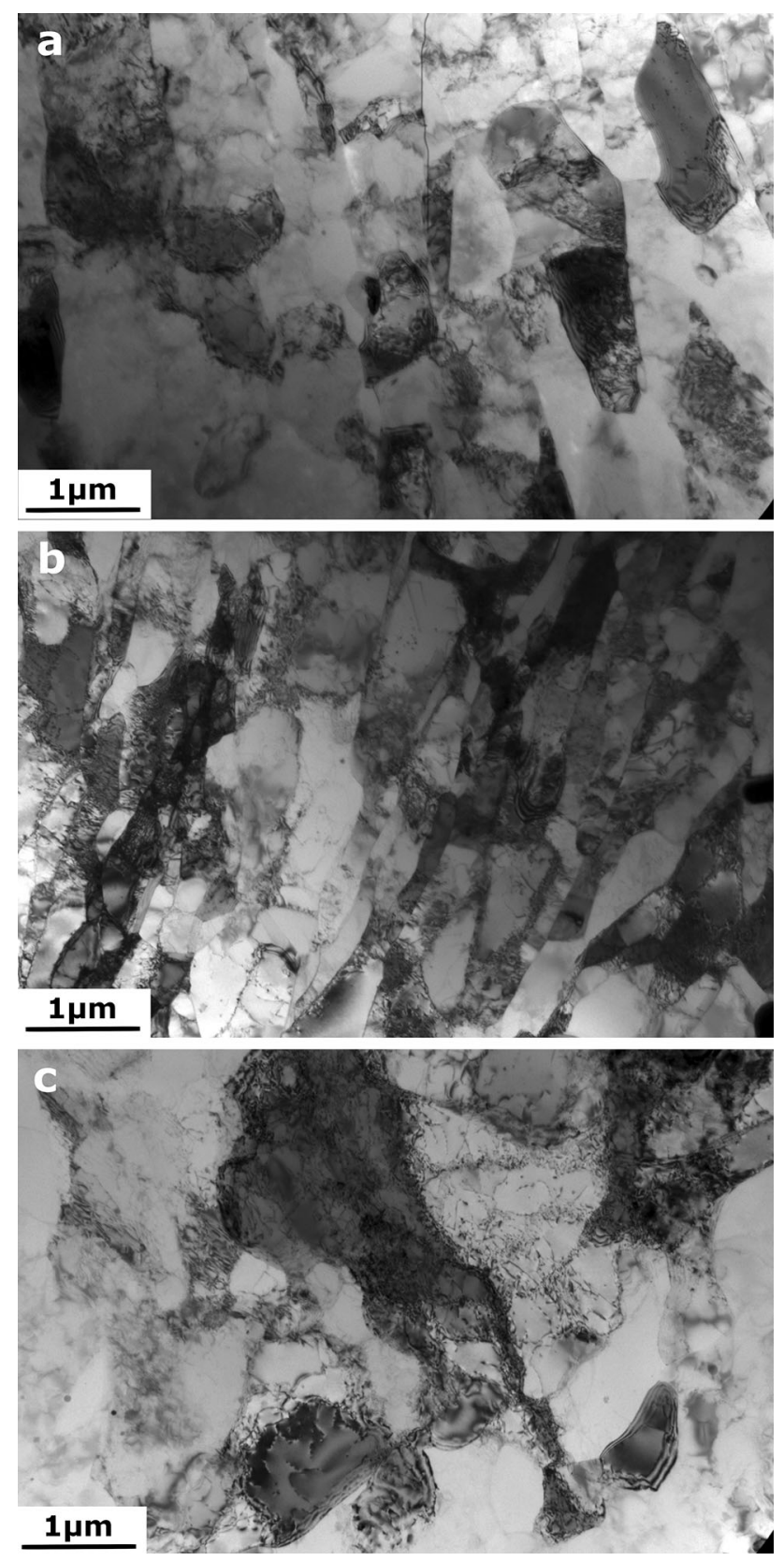

Fig. 9-The microstructure of AA 6060 after one pass of I-ECAP (a) plane $\mathrm{X},(b)$ plane $\mathrm{Y},(c)$ plane $\mathrm{Z}$.

glide so easily. As a result, the presence of dense dislocation walls was accompanied with relatively high dislocation density between them. In the case of aluminum alloys, in Reference 35 it was proven that the additions of $\mathrm{Mg}$ and $\mathrm{Si}$ are the most effective in terms of lowering the stacking fault energy. The experimental evidence was presented, confirming that pure aluminum dynamically recovers during the ECAP deformation. The Al-Mg-Si alloy, which was deformed the same way, stored dislocations in the established UFG structure. ${ }^{[51]}$ Another evidence of the change in the deformation mechanism was provided in Reference 52 where deformation twins were found in the $\mathrm{Al}-\mathrm{Mg}-\mathrm{Si}$ alloy after eight ECAP passes.
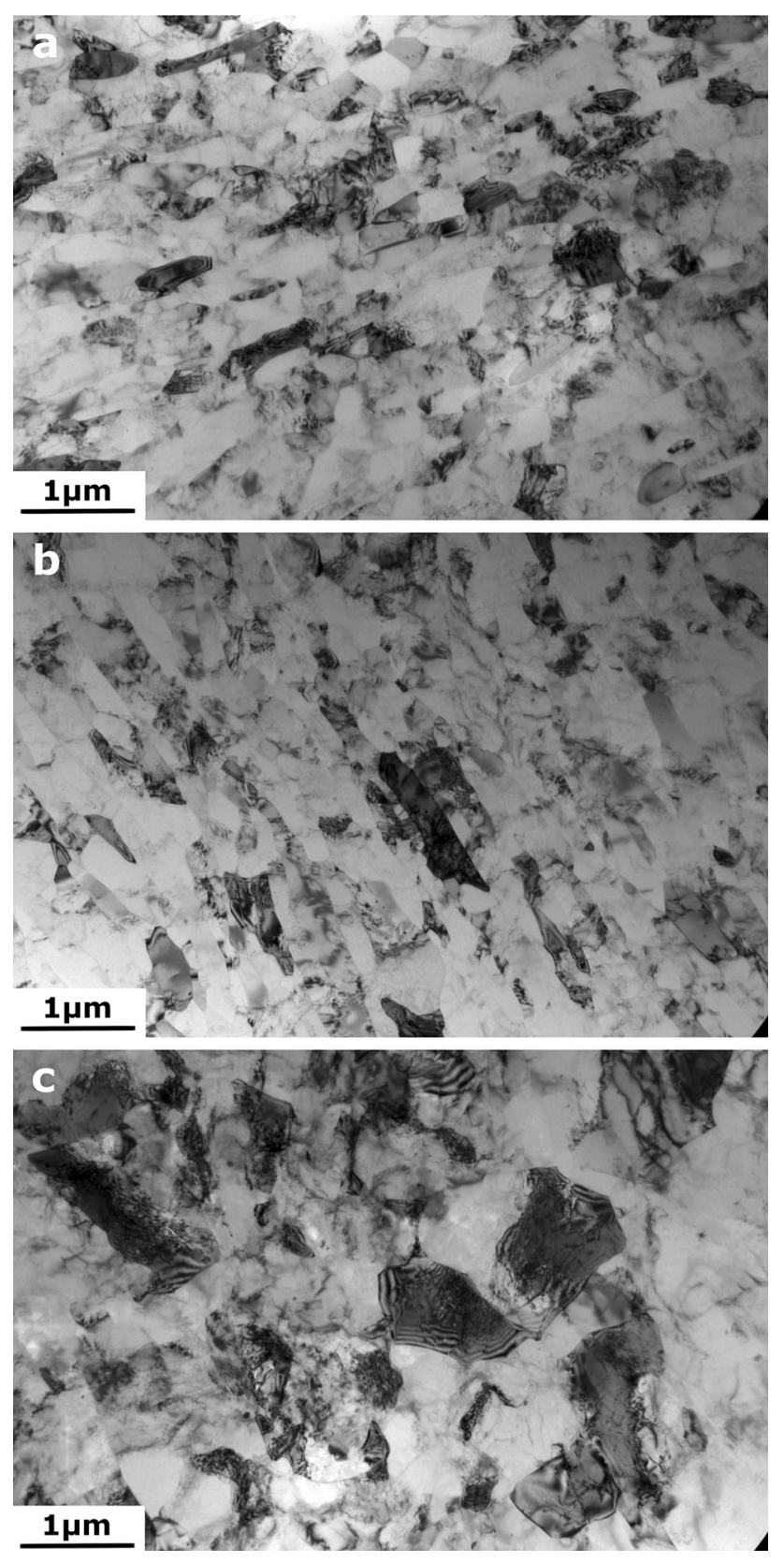

Fig. 10-The microstructure of AA 6060 after four passes of I-ECAP $(a)$ plane $\mathrm{X},(b)$ plane $\mathrm{Y},(c)$ plane $\mathrm{Z}$.

Lower dislocation mobility in aluminum alloys results in less frequent dislocation jogging and less effective establishment of the cellular substructure than in pure aluminum. As a result, grains of a relatively big size are formed at early I-ECAP stages, which do not refine by further subdivision but most likely during further rotation. Only slight changes in the grain size between the first and the fourth pass are seen as shown in Table II. On the other hand, grain rotations are considered to occur more efficiently in an alloy than in a pure metal as the former possesses a higher HAGBs fraction. Hence, it can be deduced that grain rotations occur more likely than new boundaries being established from the second to the fourth pass. As an evidence, high 
dislocation densities are present inside grains in the Al-Mg-Si alloy, which do not form any organized structures. Such microstructures were not reported in pure aluminum. ${ }^{[25,51]}$

When discussing the mechanism of grain refinement, one should highlight the role of the chosen deformation route. As in the traditional ECAP process, in I-ECAP one can distinguish various processing routes, called $\mathrm{A}$, $\mathrm{B}$, and $\mathrm{C}$. $^{[49]}$ The differences are in the rotation around the longitudinal axis of the billet. Deformation routes have a crucial impact on the size and shape of the grains after deformation, which is caused by the activation of different slip systems. In conventional ECAP, route A is based on pressing the sample without rotation. In route $\mathrm{B}_{\mathrm{A}}$ and $\mathrm{B}_{\mathrm{C}}$, the sample is rotated through 90 deg in the opposite and the same direction between each pass, respectively. In route $\mathrm{C}$, the sample is rotated through $180 \mathrm{deg}$ between passes. The route applied here was the one with a rotation around the $Z$ axis by $90 \mathrm{deg}$, which differs from route $\mathrm{B}_{\mathrm{C}}$, where $90 \mathrm{deg}$ rotation around $X$ axis is performed. Route $B_{C}$ in bar or rod samples is attributed to larger angular ranges of shearing planes when comparing other routes as well as to a restoration of the cubic unit after every fourth pass. ${ }^{[3]}$ Furthermore, the deformation is periodical and stress reversion occurs in each of the four passes, which enables more equiaxial microstructure formation. For plate samples with the rotation by $90 \mathrm{deg}$ around $Z$ axis these three criteria are not fulfilled, because no stress reversion is possible. ${ }^{[21]}$ On the other hand, the change in the flow direction activates different shear planes during each pass. Nevertheless, shearing always occurs in the same direction from the same top surface (which has contact with a tool responsible for deformation). This makes the process of grain refinement more efficient since different sets of slip systems are activated at each pass. Additionally, pressing the same surface causes the lack of redundant strain. The former is required for intense grain rotations. ${ }^{[53]}$

In case of 6xxx alloys, where SFE is reduced in comparison to pure aluminum, the dislocation mobility is lower. Therefore, the transverse LAGBs, which could refine the microstructure and cause more equiaxial microstructure, are not observed so frequently. As a result, more elongated grains are present in the microstructure. Moreover, a proof for different refinement mechanism, which is an evidence for grain rotation, is seen in Table II. There is only a small difference in average grain size between sample after one $(\sim 1.3$ to $1.4 \mu \mathrm{m})$ and four I-ECAP passes (about $0.9 \mu \mathrm{m})$. However, the misorientation angles are significantly shifted towards higher angles (Figure 5), indicating more pronounced grain rotation than grain fragmentation.

In pole figures presented in Figure 6 it can be seen that despite complex deformation route, some texture components related with simple shear can be noticed. They can be the result of the last I-ECAP pass. Every deformation stage changes the $\mathrm{X}$ and $\mathrm{Y}$ planes ${ }^{[54]}$ so the texture should be randomized. If pole figures are prepared with the use of data points gathered on the $\mathrm{Y}$ plane according to the last deformation direction, in the former it was the $\mathrm{X}$ plane with different texture components. Then, identified $\mathrm{A} / \mathrm{B}$ or $\mathrm{C}$ orientations are undoubtedly the result of the last shearing.

\section{B. Improvement in Mechanical Properties}

Microhardness measurements revealed its significant improvement in the samples subjected to I-ECAP, which can be attributed to two mechanisms - grain boundaries and dislocations strengthening. Especially at early stage of deformation the dislocations impact is very high ${ }^{[55]}$ and decreases with increasing applied strain, as the formation of new grains is more advanced and HAGBs are in majority.

The values of microhardness were not equal throughout the plate thickness. Close to the bottom surface, a distinct drop was noticed. Microhardness inhomogeneities were observed in other papers devoted to ECAP $^{[56]}$ and extrusion. ${ }^{[57]}$ It is caused by the 'dead zone' close to the bottom surface in ECAP, which occurs when the billet is no longer in contact with the die wall. Despite the homogenization of the microstructure, even after eight passes of ECAP the microhardness was not at the same level throughout the billet ${ }^{[56]}$ and for large imposed strain, the lower values of microhardness in the bottom surface remain adjacent, as in References 58 and 59. In the case of the I-ECAP process, another factor could influence the inhomogeneities in microhardness measurements. During the deformation using the chosen route with a rotation around the $Z$ axis, the tool, which is responsible for the punch motion, is in the direct contact only with the top surface. It was proven on the basis of the FE simulation that in I-ECAP the shearing process results in uniform plastic deformation. The exception is for a layer close to the punch, ${ }^{[60]}$ where the occurring strain is higher than in the rest of the sample. It explains the higher values of microhardness close to the top surface in the deformed samples. However, the value of this additional strain strongly depends on the geometry of the working surface of the punch and the direction of the punch movement relative to the billet. It can be optimized for each I-ECAP tool arrangement. However, the differences in microhardness are lower than for Al-Mg-Si alloy deformed using ECAP, ${ }^{[56]}$ indicating higher efficiency of I-ECAP in the formation of homogenous microstructure in comparison to other SPD techniques.

The results of tensile tests revealed that the ultimate tensile strength increased more than twice, whereas the yield strength - more than threefold. The enhancement in mechanical strength is caused by the grain boundaries and dislocations strengthening. The first one is quantitatively described by the Hall-Petch relation. ${ }^{[61,62]}$ It was demonstrated that it is the most effective mechanism for strength improvement in the nanostructured aluminum alloys. ${ }^{[63]}$ Nonetheless, the ductility of such materials is significantly reduced, which is caused by the limited work hardening rate and early necking to fracture.

In general, the higher strength the lower ductility, which is in particular visible for work hardened materials. However, the strength-to-ductility ratio of severely deformed materials can be improved, and there are a few options to achieve it. Firstly, the ductility of even 
high-strength aluminum alloys can be enhanced by optimizing the proportions of HAGBs and LAGBs. HAGBs increase the required energy for the activation slip between the adjacent grains. Therefore, the strengthening occurs. LAGBs, which are not as effective barriers to the gliding of mobile dislocations, can accommodate plastic deformation by amplifying the dislocation glide. As was shown, the microstructure, which consisted of lamellar grains with LAGBs in their interiors revealed enhanced uniform elongation and elongation to break, while preserving high strength. ${ }^{[4-66]}$ Different approaches were summarized in Reference 67, where simultaneous enhancement in strength and ductility were explained by the grain boundary sliding even at room temperature, possible due to increase of the strain rate sensitivity, higher fraction of $\mathrm{HABG}$ and enhanced grain boundary diffusion in materials deformed with higher strains. It can explain the results in present study, where after the fourth pass of I-ECAP the uniform elongation was higher than after only one pass.

It should be emphasized that I-ECAP-processed samples exhibit relatively low anisotropy of strength and plasticity. It makes such materials attractive for further processing, e.g., via deep drawing. In the present work, after four I-ECAP passes, the differences between transverse and longitudinal directions equal 1.8 pct for YS and 19.7 pct for elongation to break (in relation to the lower value). For comparison, such differences for AA 5086 after 8 passes of ARB equal about 15 pct for YS and 50 pet for elongation to break. ${ }^{[19]}$ In the case of different materials, the anisotropy can be even higher. For pure $\mathrm{Mg}$, where depending on the ARB temperature, the differences for YS equal 20 to 40 pct and for elongation equal from 33 pet to more than 300 pct after four passes of $\mathrm{ARB}^{[68]}$ Even after imposing a relatively small strain when rolling the Al-Mg-Si alloy $(\varepsilon=1.38)$, the changes are visible: $Y S-1.4 \mathrm{pct}, A-33$ pct, ${ }^{[69]}$ which were able to be reduced by rolling at the cryogenic temperature.

The AA6060 after SPD was not thoroughly investigated in the past. Therefore, there is a limited number of papers, which could be compared directly in terms of obtained mechanical properties and thus the I-ECAP efficiency. In this study, the microhardness increased from $43 \mathrm{Hv} 0.2$ for the initial state to $73 \mathrm{Hv} 0.2$ after four I-ECAP passes. The values of UTS and YS after deformation increased by 140 and 260 pct, respectively. The results for AA 6061 after four passes of the traditional ECAP, route $\mathrm{B}_{\mathrm{C}}$, and a $90 \mathrm{deg}$ die, reveal doubled microhardness in the $\mathrm{Y}$ plane, ${ }^{[70,71]}$ but a comparable value of UTS. ${ }^{[71]}$ Moreover, the fluctuations of microhardness obtained in the present study are lower comparing the AA6005 results after four passes of ECAP, where the $\mathrm{Hv}$ values varied from 70 to $85 .{ }^{[56]}$ Also, for pure Al deformed using ECAP, the overall homogeneity increased with subsequent passes, but even after four passes, the differences between top and bottom surfaces equaled more than $10 \mathrm{Hv}$, after six passes - $6 \mathrm{Hv} \cdot{ }^{[58]}$ In the case of AA6061 deformed via ECAP, the differences were even higher - about $40 \mathrm{Hv}$ after four passes and $20 \mathrm{Hv}$ after six passes. ${ }^{[59]}$ The achieved grain refinement and improvement in mechanical properties of AA6060 in the present study are extraordinarily promising in terms of further applications. Nevertheless, plastic deformation at elevated temperature can cause further enhancement in grain refinement and mechanical strength improvement. As was shown for AA6060, the most efficient grain refinement was achieved for HPT process conducted at temperature of $373 \mathrm{~K}\left(100{ }^{\circ} \mathrm{C}\right)$, which was attributed to the strong solute segregation at grain boundaries at present conditions. ${ }^{[31]}$ Similarly, dynamic aging of AA6061 during ECAP caused the highest increase in hardness. ${ }^{[28]}$

The aluminum alloys from $6 \mathrm{xxx}$ series are precipitation hardenable. It was proved that very high mechanical strength can be obtained by combining SPD processes also with post-processed aging treatment. For AA6056 after two passes of ECAP and subsequent peak aging at $443 \mathrm{~K}\left(170{ }^{\circ} \mathrm{C}\right)$ the value of yield stress was $430 \mathrm{MPa}$ and it was the enhancement of approximately 25 pct compared to peak-aged coarse-grained counterparts. ${ }^{[72]}$ Even higher increase was obtained for the AA6060 after extrusion and subsequent aging at $443 \mathrm{~K}\left(170{ }^{\circ} \mathrm{C}\right)$. The coarse-grained peak-aged alloy revealed the UTS of $213 \mathrm{MPa}$, while after one extrusion and then aging this value increased about 35 pct. The maximum of UTS was achieved for sample aged after eight passes of extrusion and equaled $338 \mathrm{MPa}$, which was 55 pct higher than for the reference material. ${ }^{[73]}$ Not only strength improvement in post-processing aging of Al-Mg-Si alloy, ${ }^{[74]}$ but also changes in precipitates sequence can be obtained, ${ }^{[33]}$ as a result of thermal shocks during plastic deformation. This work is not dedicated to the precipitation phenomenon in the UFG materials. Therefore, samples in the as-annealed state with a low strength were chosen as the initial. Nevertheless, as can be seen from presented results there is an immense potential for obtaining higher mechanical properties by implementing aging process.

\section{Fabrication of UFG Plates and Sheets}

Most frequently, the UFG sheets are produced by means of $A R B,{ }^{[17]}$ which appears to be relatively uncomplicated and easily applicable. Standard hot rolling machinery can be used with hardly any need for modification. Other advantages include the high productivity rate and a practically unlimited amount of material, which can be produced. Nevertheless, there are some limitations of this method, for example, the necessity of proper surface preparation in order to obtain satisfactory bonding between layers. For some materials, there is a need for rolling at elevated temperatures, which dramatically reduces the grain refinement efficiency. Furthermore, ARB causes significant anisotropy of mechanical properties. ${ }^{[75]}$ Finally, one of the most important drawbacks is the fracture of deformed materials. Especially at higher cycles, edge cracks occur, which propagate into the center of the sheet. ${ }^{[20]}$

The UFG plates can also be produced by the conventional ECAP, as described in Reference 21. The main advantage of ECAP over ARB is the significant reduction of a morphological texture, which leads to more isotropic mechanical properties. However, pressing of plates using the conventional ECAP is relatively 
difficult due to high friction forces between the billet and the channel. The results obtained in the present study clearly demonstrated that I-ECAP is as effective as the processes mentioned above and even easier to execute because of the reduction in friction forces due to implemented incremental shear. One of the major advantages is also the possibility of processing large billets with various dimensions. Moreover, obtained samples, as described in the present paper, reveal low anisotropy of mechanical properties, which is promising in the case of possible applications.

\section{CONCLUSIONS}

(1) It was demonstrated that I-ECAP can be successfully applied to refine the microstructure of commercially available Al-Mg-Si alloys. After four passes, the average grain size was reduced to below $1 \mu \mathrm{m}$ with the content of HAGBs of about 53 to 57 pct. The employed method allowed producing UFG AA6060 plates.

(2) The mechanism of grain refinement in $\mathrm{Al}-\mathrm{Mg}-\mathrm{Si}$ alloy is distinctly different from that in pure aluminum with the grain rotation being more prominent than the grain subdivision. This was attributed to lower stacking fault energy and the reduced mobility of dislocations in the alloy.

(3) The UFG Al-Mg-Si plates produced by means of I-ECAP exhibit relative homogeneity across the thickness. Nevertheless, the fluctuations in microhardness between the top and bottom surface are observed and equals about 3 pct after four passes.

(4) The UFG plates obtained via the I-ECAP processing exhibit a very good combination of strength and ductility (about $220 \mathrm{MPa}$ in YS and $\sim 10$ pct in elongation) but limited uniform elongation, estimated below 3 pct. Also, very low anisotropy of mechanical properties in comparison with other SPD processing methods was achieved. In terms of YS, the difference between the longitudinal and transverse direction amounts to less than 2 pct. Such properties make plates attractive for further processing and applications.

\section{ACKNOWLEDGMENT}

This research was financed by the National Centre for Research and Development in Poland within the project "Properties and longterm behaviour of dissimilar joints of advanced materials for lightweight structures in energy saving applications" (Contract no. WPN/6/2013).

\section{OPEN ACCESS}

This article is distributed under the terms of the Creative Commons Attribution 4.0 International License (http://creativecommons.org/licenses/by/4.0/), which permits unrestricted use, distribution, and reproduction in any medium, provided you give appropriate credit to the original author(s) and the source, provide a link to the Creative Commons license, and indicate if changes were made.

\section{REFERENCES}

1. M.A. Meyers, A. Mishra, and D.J. Benson: Prog. Mater. Sci., 2006, vol. 51, pp. 427-56.

2. M. Furukawa, Z. Horita, M. Nemoto, and T.G. Langdon: Mater. Sci. Eng. A, 2002, vol. 324, pp. 82-89.

3. R.Z. Valiev and T.G. Langdon: Prog. Mater. Sci., 2006, vol. 51, pp. 881-81.

4. Y. Iwahashi, Z. Horita, M. Nemoto, and T.G. Langdon: Acta Mater., 1998, vol. 46, pp. 3317-31.

5. A.P. Zhilyaev, D.L. Swisher, K. Oh-ishi, T.G. Langdon, and T.R. McNelley: Mater. Sci. Eng. A, 2006, vol. 429, pp. 137-48.

6. S.G. Chowdhury, A. Mondal, J. Gubicza, G. Krállics, and Á. Fodor: Mater. Sci. Eng. A, 2008, vol. 490, pp. 335-42.

7. M.I.A. El Aal: Mater. Sci. Eng. A, 2011, vol. 528, pp. 6946-57.

8. K.R. Cardoso, D.N. Travessa, W.J. Botta, and A.M. Jorge: $M a-$ ter. Sci. Eng. A, 2011, vol. 528, pp. 5804-11.

9. A. Ma, Y. Nishida, K. Suzuki, I. Shigematsu, and N. Saito: Scr. Mater., 2005, vol. 52, pp. 433-37.

10. P.W.J. Mckenzie and R. Lapovok: Acta Mater., 2010, vol. 58, pp. 3198-3211.

11. G.I. Raab: Mater. Sci. Eng. A, 2005, vols. 410-411, pp. 230-33.

12. C. Xu, S. Schroeder, P.B. Berbon, and T.G. Langdon: Acta Mater., 2010, vol. 58, pp. 1379-86.

13. T.G. Langdon: Mech. Mater., 2013, vol. 67, pp. 2-8.

14. M. Kamachi, M. Furukawa, Z. Horita, and T.G. Langdon: Mater. Trans., 2004, vol. 45, pp. 2521-24.

15. M. Sarebanzadeh, R. Roumina, R. Mahmudi, G.H. Wu, and H.R. Jafari: NodooshanMater. Sci. Eng. A, 2015, vol. 646, pp. 249-53.

16. E. Mostaed, A. Fabrizi, D. Dellasega, F. Bonollo, and M. Vedani: J. Alloys Compd., 2015, vol. 638, pp. 267-76.

17. Y. Saito, H. Utsunomiya, N. Tsuji, and T. Sakai: Acta Mater., 1999, vol. 47, pp. 579-83.

18. L. Su, C. Lu, H. Li, G. Deng, and K. Tieu: Mater. Sci. Eng. A, 2014, vol. 614, pp. 148-55.

19. S. Roy, D. Satyaveer Singh, S. Suwas, S. Kumar, and K. Chattopadhyay: Mater. Sci. Eng. A, 2011, vol. 528, pp. 8469-78.

20. N. Tsuji, Y. Saito, H. Utsunomiya, and S. Tanigawa: Scr. Mater., 1999, vol. 40, pp. 795-800

21. M. Kamachi, M. Furukawa, Z. Horita, and T.G. Langdon: Mater. Sci. Eng. A, 2003, vol. 361, pp. 258-66.

22. O. Saray, G. Purcek, I. Karaman, T. Neindorf, and H.J. Maier: Mater. Sci. Eng. A, 2011, vol. 528, pp. 6573-83.

23. O. Saray, G. Purcek, and I. Karaman: Rev. Adv. Mater. Sci., 2010, vol. 25 , pp. $42-51$

24. L. Olejnik, A. Rosochowski, and M. Richert: Mater. Sci. Forum, 2008, vols. 584-586, pp. 108-13.

25. W. Chrominski, L. Olejnik, A. Rosochowski, and M. Lewandowska: Mater. Sci. Eng. A, 2015, vol. 636, pp. 172-80.

26. Olejnik L., Chrominski W., Rosochowski A., Lipinska M., Lewandowska M. (2014) IOP Conf. Ser. Mater. Sci. Eng. 63:012004.

27. H.J. Roven, M. Liu, and J.C. Werenskiold: Mater. Sci. Eng. A, 2008, vols. 483-484, pp. 54-58.

28. M. Vaseghi, A.K. Taheri, S.I. Hong, and H.S. Kim: Mater. Des., 2010, vol. 31, pp. 4076-82.

29. E. Ortiz-Cuellar, M.A.L. Hernandez-Rodriguez, and E. García-Sanchez: Wear, 2011, vol. 271, pp. 1828-32.

30. A. Loucif, R.B. Figueiredo, T. Baudin, F. Brisset, R. Chemam, and T.G. Langdon: Mater. Sci. Eng. A, 2012, vol. 532, pp. 139-45.

31. K. Tugcu, G. Sha, X.Z. Liao, P. Trimby, J.H. Xia, M.Y. Murashkin, Y. Xie, R.Z. Valiev, and S.P. Ringer: Mater. Sci. Eng. A, 2012, vol. 552, pp. 415-18.

32. R.Z. Valiev, M. Murashkin, and I. Sabirov: Scr. Mater., 2014, vol. 76, pp. 13-16. 
33. W. Chrominski and M. Lewandowska: Acta Mater., 2016, vol. 103 , pp. $547-57$.

34. X. Sauvage, E.V. Bobruk, M.Y. Murashkin, Y. Nasedkina, N.A. Enikeev, and R.Z. Valiev: Acta Mater., 2015, vol. 98, pp. 355-66.

35. M. Muzyk, Z. Pakiela, and K.J. Kurzydlowski: Scr. Mater., 2011, vol. 64, pp. 916-18.

36. Weiß O.J., Gaganidze E., Aktaa J.: Materials Challenges and Testing for Supply of Energy and Resources, Springer, New York, 2012, vol. 1, pp. 221-34.

37. J.K. Mackenzie: Biometrika Trust., 1958, vol. 45, pp. 229-40.

38. A.P. Zhilyaev, K. Ohishi, G.I. Raab, and T.R. McNelley: Mater. Sci. Eng. A, 2006, vol. 441, pp. 245-52.

39. A.A. Gazder, F. Dalla Torre, C.F. Gu, C.H.J. Davies, and E.V. Pereloma: Mater. Sci. Eng. A, 2006, vol. 415, pp. 126-39.

40. M. Cabibbo, E. Evangelista, and C. Scalabroni: Micron, 2005, vol. 36, pp. 401-14.

41. P.L. Sun, P.W. Kao, and C.P. Chang: Metall. Mater. Trans. A, 2004, vol. 35A, pp. 1359-68.

42. P. Sun, P. Kao, and C. Chang: Mater. Sci. Eng. A, 2000, vol. 283, pp. $82-85$.

43. M. Kawasaki, Z. Horita, and T.G. Langdon: Mater. Sci. Eng. A, 2009, vol. 524, pp. 143-50.

44. E.A. El-Danaf, M.S. Soliman, A.A. Almajid, and M.M. El-Rayes: Mater. Sci. Eng. A, 2007, vol. 458, pp. 226-34.

45. M. Lipińska, L. Olejnik, A. Pietras, A. Rosochowski, P. Bazarnik, J. Goliński, T. Brynk, and M. Lewandowska: Mater. Des., 2015, vol. 88 , pp. $22-31$.

46. J. Gil Sevillano, P. van Houtte, and E. Aernoudt: Prog. Mater. Sci., 1980, vol. 25, pp. 69-134.

47. D.A. Hughes and N. Hansen: Acta Mater., 1997, vol. 45, pp. 3871-86.

48. P.B. Prangnell, J.R. Bowen, and P.J. Apps: Mater. Sci. Eng. A, 2004, vols. 375-377, pp. 178-85.

49. M. Furukawa, Y. Iwahashi, Z. Horita, M. Nemoto, and T.G. Langdon: Mater. Sci. Eng. A, 1998, vol. 257, pp. 328-32.

50. D.A. Hughes and W.D. Nix: Mater. Sci. Eng. A, 1989, vol. 122, pp. $153-72$.

51. M. Hockauf and L.W. Meyer: J. Mater. Sci., 2010, vol. 45, pp. $4778-89$.

52. M. Liu, H.J. Roven, Y. Yu, and J.C. Werenskiold: Mater. Sci. Eng. A, 2008, vols. 483-484, pp. 59-63.

53. A. Gholinia, P.B. Prangnell, and M.V. Markushev: Acta Mater., 2000, vol. 48, pp. 1115-30.

54. M. Furukawa, Z. Horita, and T.G. Langdon: Mater. Sci. Eng. A, 2002, vol. 332, pp. 97-109.
55. S. Amirkhanlou, M. Askarian, M. Ketabchi, N. Azimi, N. Parvin, and F. Carreño: Mater. Charact., 2015, vol. 109, pp. $57-65$.

56. A. Veveçka, M. Cabibbo, and T.G. Langdon: Mater. Charact., 2013, vol. 84, pp. 126-33.

57. T. Kayser, B. Klusemann, H.G. Lambers, H.J. Maier, and B. Svendsen: Mater. Sci. Eng. A, 2010, vol. 527, pp. 6568-73.

58. S.N. Alhajeri, N. Gao, and T.G. Langdon: Mater. Sci. Eng. A, 2011, vol. 528, pp. 3833-40.

59. M. Prell, C. Xu, and T.G. Langdon: Mater. Sci. Eng. A, 2008, vol. 480, pp. 449-55.

60. L. Olejnik, W. Chrominski, A. Rosochowski, M. Lipinska, and M. Lewandowska: IOP Conf. Ser. Mater. Sci. Eng., 2014, vol. 63, p. 012004.

61. E.O. Hall: Proc. Phys. Soc. Sect. B., 1951, vol. 64, p. 747.

62. N.J. Petch: J. Iron Steel Inst., 1953, vol. 174, pp. 25-28.

63. I. Sabirov, M.Y. Murashkin, and R.Z. Valiev: Mater. Sci. Eng. A, 2013, vol. 560, pp. 1-24.

64. T. Niendorf, J. Dadda, D. Canadinc, H.J. Maier, and I. Karaman: Mater. Sci. Eng. A, 2009, vol. 517, pp. 225-34.

65. T. Hu, K. Ma, T.D. Topping, B. Saller, A. Yousefiani, J.M. Schoenung, and E.J. Lavernia: Scr. Mater., 2014, vols. 78-79, pp. $25-28$.

66. T. Qian, M. Marx, K. Schüler, M. Hockauf, and H. Vehoff: Acta Mater., 2010, vol. 58, pp. 2112-23.

67. N. Balasubramanian and T.G. Langdon: Metall. Mater. Trans. A, 2016, vol. 47A, pp. 5827-38.

68. H. Chang, M.Y. Zheng, K. Wu, W.M. Gan, L.B. Tong, and H.G. Brokmeier: Mater. Sci. Eng. A, 2010, vol. 527, pp. 7176-83.

69. N. Naga Krishna, M. Ashfaq, P. Susila, K. Sivaprasad, and K. Venkateswarlu: Mater. Charact., 2015, vol. 107, pp. 302-08.

70. C. Xu, M. Furukawa, Z. Horita, and T.G. Langdon: Mater. Sci. Eng. A, 2005, vol. 398, pp. 66-76.

71. J. Wongsa-Ngam, M. Kawasaki, and T.G. Langdon: Mater. Sci. Eng. A, 2012, vol. 556, pp. 526-32.

72. K. Hockauf, L.W. Meyer, M. Hockauf, and T. Halle: J. Mater. Sci., 2010, vol. 45, pp. 4754-60.

73. M. Hockauf, L.W. Meyer, B. Zillmann, M. Hietschold, S. Schulze, and L. Krüger: Mater. Sci. Eng. A, 2009, vol. 503, pp. $167-71$

74. W. Chrominski, M. Kulczyk, M. Lewandowska, and K.J. Kurzydlowski: Mater. Sci. Eng. A, 2014, vol. 609, pp. 80-87.

75. B. Beausir, J. Scharnweber, J. Jaschinski, H.-G. Brokmeier, C.-G. Oertel, and W. Skrotzki: Mater. Sci. Eng. A, 2010, vol. 527, pp. 3271-78. 